\title{
Effects of Freezing and Thawing Cycle on Mechanical Properties and Stability of Soft Rock Slope
}

\author{
Yanlong Chen, ${ }^{1,2}$ Peng $\mathrm{Wu},{ }^{3}$ Qing Yu, ${ }^{4}$ and Guang $\mathrm{Xu}^{5}$ \\ ${ }^{1}$ State Key Laboratory for Geomechanics and Deep Underground Engineering, China University of Mining \& Technology, \\ Xuzhou 221116, China \\ ${ }^{2}$ School of Mechanics and Civil Engineering, China University of Mining \& Technology, Xuzhou 221116, China \\ ${ }^{3}$ School of Mines, China University of Mining \& Technology, Xuzhou 221116, China \\ ${ }^{4}$ School of Resources and Geosciences, China University of Mining \& Technology, Xuzhou 221116, China \\ ${ }^{5}$ Department of Mining Engineering \& Metallurgical Engineering, Western Australian School of Mines, Curtin University, \\ Kalgoorlie, WA 6430, Australia
}

Correspondence should be addressed to Yanlong Chen; chenyanlong@cumt.edu.cn

Received 27 July 2017; Accepted 18 October 2017; Published 6 November 2017

Academic Editor: Jun Liu

Copyright (C) 2017 Yanlong Chen et al. This is an open access article distributed under the Creative Commons Attribution License, which permits unrestricted use, distribution, and reproduction in any medium, provided the original work is properly cited.

\begin{abstract}
To explore the variation laws of mechanical parameters of soft rock and the formed slope stability, an experiment was carried out with collected soft rock material specimens and freezing and thawing cycle was designed. Meanwhile, a computational simulation analysis of the freezing-thawing slope stability was implemented. Key factors that influence the strength of frozen rock specimens were analyzed. Results showed that moisture content and the number of freezing-thawing cycles influenced mechanical parameters of soft rock significantly. With the increase of moisture content, cohesion of frozen soft rock specimens presents a quadratic function decrease and the internal friction angle shows a negative exponential decrease. The stability coefficient of soft rock material slope in seasonal freeze soil area declines continuously. With the increase of freezing and thawing cycle, both cohesion and internal friction angle of soft rock decrease exponentially. The higher the moisture content, the quicker the reduction. Such stability coefficient presents a negative exponential reduction. After three freezing and thawing cycles, the slope stability coefficient only changes slightly. Findings were finally verified by the filed database.
\end{abstract}

\section{Introduction}

Slope is a steep hill with a certain angle, and it is composed of soil and rocks. It is the most common rock engineering structure [1]. Open-pit mining forms slopes with big geometric size. Safety and stability of open-pit mine slope are of the important factors that restrict safe and high-efficient production of the mine [2-5]. Deformation and failure of big slopes cause huge economic losses and even threaten life safety of workers [6-12]. The shear strength of slope rocks is a basic parameter that determines slope stability, which is influenced greatly by external factors. Temperature fields affect mechanical properties of rocks significantly, especially for rocks with high moisture content and low stiffness [13-19]. In China, coal resources are mainly in northern areas which have more than 10 open-pit coal mines with an annual output of over $20 \mathrm{Mt}$. These regions belong to seasonal freezing soil areas. Due to temperature rise and drops during season changing, rocks experience physical freezing and thawing cycle, which is easy to cause various slope failures, such as frost heaving, rock mass denudation, and creep deformation. Freezing and thawing cycles cause the development of rock fractures, degrade physical and mechanical properties of rock-soil mass, reduce slope strength, and thus easily result in landslide accidents [20,21].

Many scholars have made long-term researches on freezing and thawing problems of slope. A set of unique mechanical theoretical systems based on damage mechanism of rock and soil have been developed [22]. The variation of physical and mechanical properties of rock with defects (e.g., joint fissure) under freezing and thawing cycle and phase changes and moisture and heat transfer characteristics caused by 
freezing of free water inside the slope were investigated [23]. The evolution of macro- and microdamage of rocks caused by different temperature histories and moisture (ice) contents was also studied. Such mechanical theory provides theoretical guidance to the design and construction of rock engineering in cold regions [24].

Existing theoretical and experimental researches concerning the effect of low temperature range (generally less than $0^{\circ} \mathrm{C}$ ) on physical and mechanical properties of rocks could be divided into three types. The first type, which is based on continuum mechanics and the classical heat transfer theory, studies thermal-hydro-mechanical (THM) coupling of rocks under low temperature and the freezing and thawing cycles [25], as well as distribution laws of frost heaving pressure influenced by frost heaving and temperature on tunnel surrounding rocks in cold regions $[26,27]$. The second type studies basic mechanical properties of rocks under freezing and thawing cycles based on damage mechanics. Nicholson et al. [28] analyzed damage deterioration of 10 kinds of rocks caused by freezing and thawing cycles and studied the macroscopic freezing and thawing damage evolution of rocks through graphic record. Li and others [29] studied freezing and thawing microscopic damage of rocks by using advanced Computed Tomography (CT) scanning technique and attempted to establish a damage constitutive model that uses $\mathrm{CT}$ as the freezing and thawing damage variable. Based on related theory of fracture mechanics, the third type studies crack development and failure criterion of cracked rocks under freezing, thawing, and the freezing and thawing cycles $[30,31]$.

China's coal resources are mainly located in the northern areas which belong to the seasonal frozen soil area and experience complete freezing and thawing cycles annually. Due to the mining conditions, open-pit is the preferred mining method in this area. Therefore, a great number of high steep slopes are constructed. Few researches on slope engineering of open-pit mines explore the influence mechanism of freezing and thawing cycles on slope deformation and stability. In seasonal freezing soil areas, strength, moisture content, deformation features, and mechanical parameters of soft rock slope are significantly different than other areas. Therefore, researches on deformation and stability of slope under freezing and thawing conditions shall be based on its mechanical states and corresponding physical and mechanical parameters. Long-term engineering practices have already proved that the freezing and thawing cycles play an important role in influencing the stability failure of slopes. As a result, studying frost heaving characteristics of rocks, physical and mechanical parameters, and stability of soft rock slope during the freezing and thawing cycles has very important engineering value and safety significance to open-pit mines in North China.

\section{Effect of Regional Geology and the Freezing and Thawing Cycles on Slope}

2.1. Introduction of Wulin Open-Pit Mine. The Wulin openpit mine lies in Linkou County, North China (Figure 1). It is

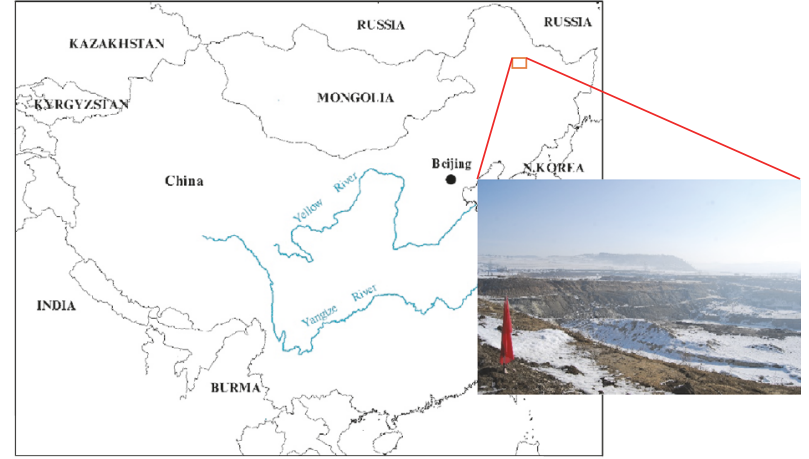

FIGURE 1: Location of the study area.

surrounded by railways and highways and thus has convenient transport conditions. The whole ore field, in average, is $5.2 \mathrm{~km}$ long and $0.82 \mathrm{~km}$ wide, covering an area of $4.3 \mathrm{~km}^{2}$. The mine lot belongs to hilly slope in terrain and valley plain in landform, showing a relatively simple structure. The lowest temperature of the covering area is in January $\left(-30.3^{\circ} \mathrm{C}\right.$, $-17.7^{\circ} \mathrm{C}$ in average) and the highest temperature is in July $\left(29.7^{\circ} \mathrm{C}, 22.6^{\circ} \mathrm{C}\right.$ in average). The maximum freezing depth of soil is $2 \mathrm{~m}$.

2.2. Effect of Freezing and Thawing Factors. The area covered within the Wulin mine belongs to the typical seasonal freezing soil area. The surface soil begins to be frozen gradually after November. The freezing soil thickness increases gradually until reaching the maximum. Then, the surface and the maximum underground freezing depth begin to thaw in March. The freezing layer between the surface and the maximum underground freezing depth is called the seasonal freezing layer. November is viewed as the typical freezing period of the mine, while March is viewed as the typical thawing period. Time from November to March is viewed as the frozen period.

The seasonal freezing layer experiences both freezing and thawing in one year, thus producing frost heaving and thaw collapse of unfrozen water in soil. Freezing causes heaves at some positions of the slope, increases the overall stiffness, and changes the slope flatness. Thawing causes rough and uneven rock-soil mass on the slope surface and working benches as well as muddy road surface and thus influences production efficiency. After entering into the thawing period, different scales of landslides on the superficial slope layer frequently occur, threatening safety of workers and equipment. Freezing and thawing are the key influencing factors of slope stability in this mine.

\section{Experiments}

3.1. The Shearing Experimental System. The whole test system structure is shown in Figure 2. The system is composed of the following three parts.

(1) Multifunction Frozen Soil Simulation System. The frozen soil test system has good heat insulation performance. The 


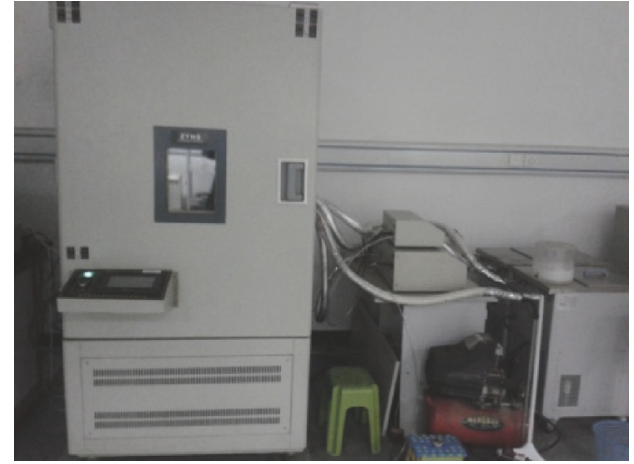

(a) Frozen soil simulation system

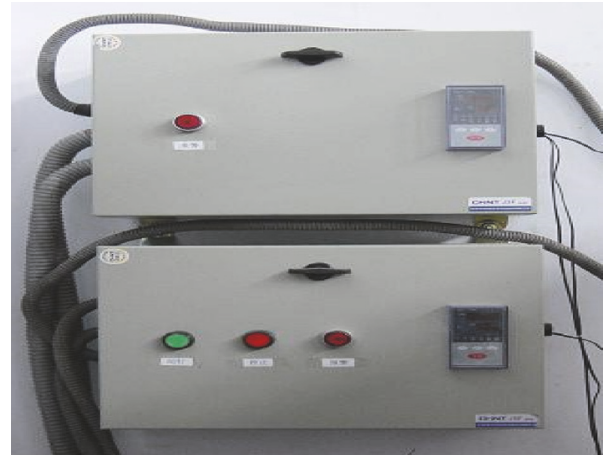

(c) Temperature control system

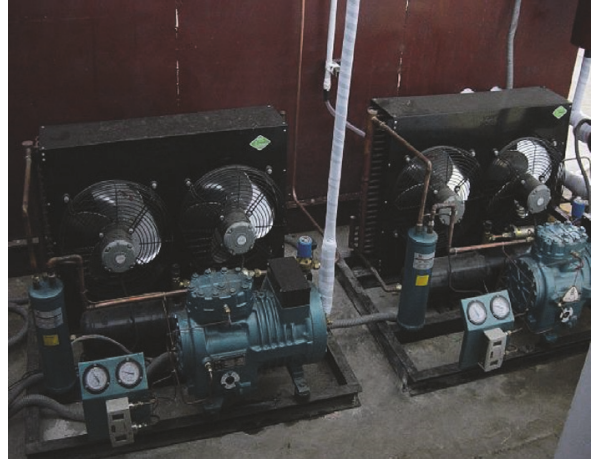

(b) Cooling system

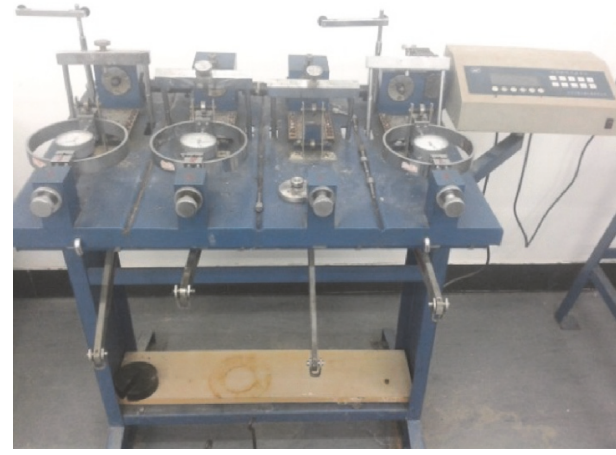

(d) Shear test system

Figure 2: Test system.

inner wall has a $150 \mathrm{~mm}$ thick polyurethane insulation coating and the thermal insulation material on the external wall could reduce temperature influence and ensure high accuracy of test results.

(2) Cooling and Temperature Control System. The cooling system and temperature control system provide the experimental environment. The used cooling system consists of two independent cooling devices, which could provide low temperature environment. The control accuracy and display accuracy are $0.5^{\circ} \mathrm{C}$ and $0.1^{\circ} \mathrm{C}$, respectively.

(3) Shear Test System. The test system is equipped with one EDJ-1 strain-controlled direct shear apparatus. The diameter of the cutting ring is $61.8 \mathrm{~mm}$, the height is $20 \mathrm{~mm}$, and the shear velocity is $0.8 \mathrm{~mm} / \mathrm{min}$.

Since metals are sensitive to temperature, temperature change will directly influence technical parameters of the dynameter ring. Effect of temperature on the dynameter ring was corrected through three times of prepressing with the maximum load under different temperature environment. The correcting algorithm is

$$
A=A_{0}\left[1+\alpha\left(t-t_{0}\right)\right],
$$

where $A$ is the corrected value of the dynameter ring $(\mathrm{kPa} / 0.01 \mathrm{~mm}), A_{0}$ is the original value of the dynameter ring $(\mathrm{kPa} / 0.01 \mathrm{~mm}), t$ is the service temperature of the dynameter ring $\left({ }^{\circ} \mathrm{C}\right), t_{0}$ is the setting temperature of the dynameter ring $\left({ }^{\circ} \mathrm{C}\right)$, and $\alpha$ is temperature correction factor $\left(0.0003 /{ }^{\circ} \mathrm{C}\right)$.

\subsection{Shear Test Design and Procedures}

(1) Sample Preparation. The specimens were collected from the south end-wall slope of Wulin open-pit mine, and the principal component of the rock specimen is siltstone with the grain size of $0.1 \mathrm{~mm}$. It is known the average unit weight of the rock specimen is about $18.3 \mathrm{kN} / \mathrm{m}^{3}$, and the natural moisture content is about $15.3 \%$. In the laboratory, the specimens were made into the standard samples with the diameter of $61.8 \mathrm{~mm}$ and $20 \mathrm{~mm}$ high, as shown in Figure 3.

It is important to make sure the rock specimens used in the laboratory have the similar properties with the natural state, so that the experimental results found in the presented research could be representative of the real behavior experienced by the materials under consideration. In addition, the required amount of water will be added to the rock specimen during its preparation, so that the moisture content is the same with the original state.

(2) Test Conditions and Steps. Using the control variable method, this experiment prepared freezing rock specimens by changing the initial moisture content, number of freezing and thawing cycle, and freezing and thawing temperature one by one. Then, mechanical strength of prepared specimens was tested through the direct shear test. Based on the statistical 

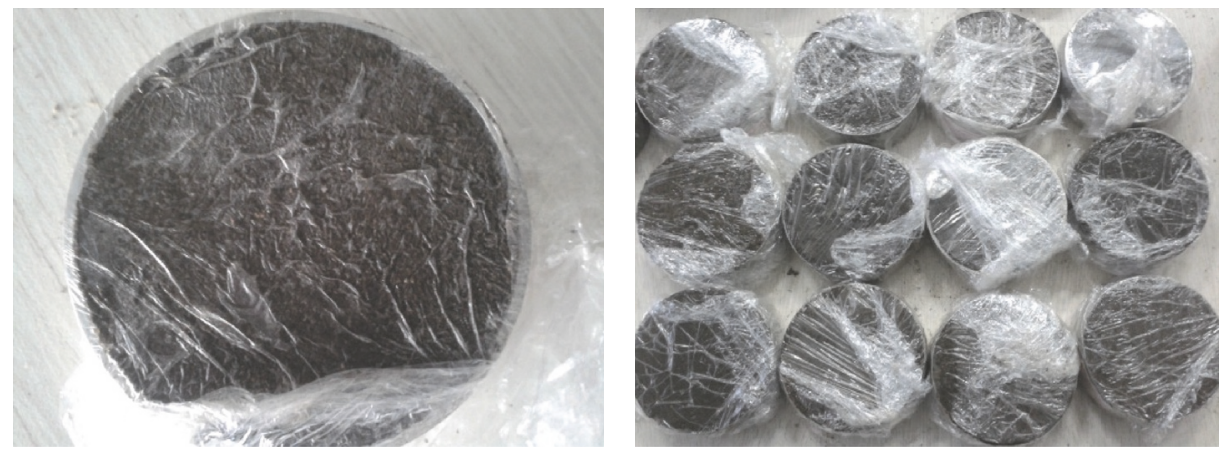

FIgURE 3: Standard specimens.

analysis of test results, the studies impact of the studied factors on mechanical properties of weakly consolidated soft rock was disclosed. Different conditions for soft rock sample preparation and direct shear test are set according to the following:

(a) The freezing and thawing temperature varied in the range $-20^{\circ} \mathrm{C} \sim+20^{\circ} \mathrm{C}$ in each freezing and thawing cycle; the initial moisture content of rock specimens was set to $15.3 \%$, $18.1 \%, 20.3 \%$, and $23 \%$.

(b) The initial moisture content of rock specimens was kept as constant. The freezing and thawing temperature range varied in the range $-20^{\circ} \mathrm{C} \sim+20^{\circ} \mathrm{C}$. The number of freezing and thawing cycle was set to $1,2,3$, and 5 .

(c) The initial moisture content and number of freezing and thawing cycle were kept as constants, but the freezing and thawing temperature range was set to $-20^{\circ} \mathrm{C} \sim+20^{\circ} \mathrm{C},-15^{\circ} \mathrm{C} \sim$ $+15^{\circ} \mathrm{C},-10^{\circ} \mathrm{C} \sim+10^{\circ} \mathrm{C}$, and $-5^{\circ} \mathrm{C} \sim+5^{\circ} \mathrm{C}$.

The specific test steps are as follows:

(a) Specimens are prepared in the low temperature freezing soil simulation system in a group of four. Prepared specimens are put into the constant temperature cabinet and frozen under $-20^{\circ} \mathrm{C}$ for $12 \mathrm{~h}$.

(b) Adjust the temperature of the simulation system to the test designed temperature, and maintain it for $24 \mathrm{~h}$.

(c) Specimens are put in the simulation system for insulation treatment. Thermistor is used for the purpose of realtime temperature measurement. The direct shear test starts after the temperature reaches the designed value.

(d) Coat the inner wall of the direct shear test box with Vaseline. Put specimens into the box and implement the shear test under four different normal loads. The shear velocity shall be controlled at $0.8 \mathrm{~mm} / \mathrm{min}$. Data are recorded during tests.

(e) Cohesion and internal friction angle are calculated based on the test results.

3.3. Shear Test Data Processing and Analysis. To explore the influence of key factors on the strength of frozen rock specimens, several groups of freezing and thawing experiments were conducted with rock specimens collected from the Wulin mine. The orthogonal experimental design was employed to reduce the amount of the experimental work. Experiment results and mechanical parameters of soil sample with $23 \%$ water content are shown in Figures 4 and 5. The experiment was optimized uniformly according to the

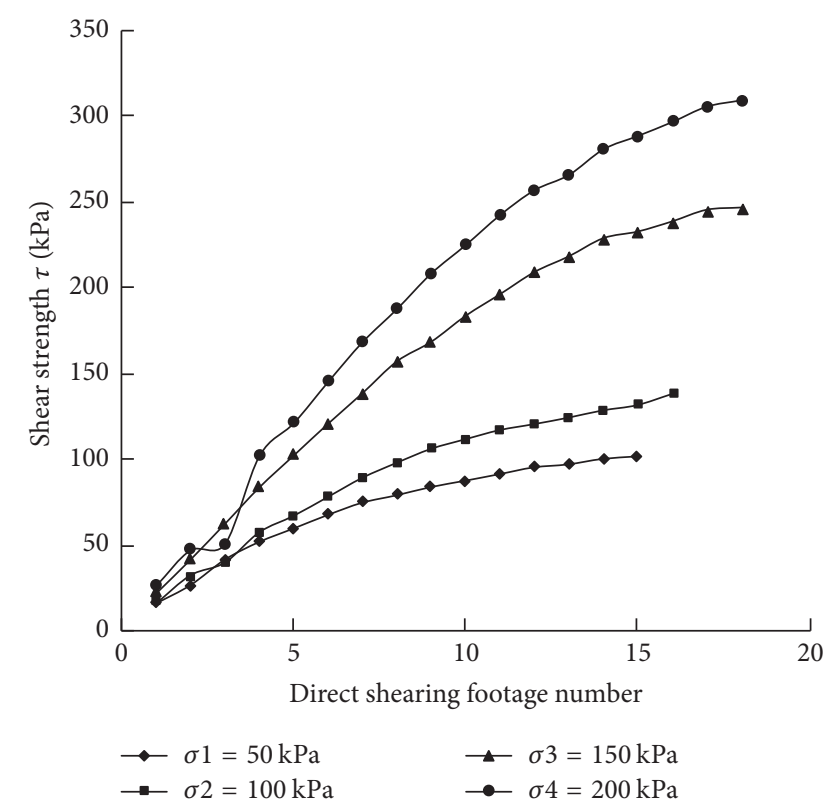

FIGURE 4: Direct shear experimental results.

principle of three factors and four levels. The experimental design and the test data are shown in Table 1.

It can be seen from Table 1 that the moisture content and number of the freezing and thawing cycles significantly influence mechanical parameters of the frozen soft rock, while the freezing and thawing temperature is less significant. Therefore, this paper focused on studying the influence of initial moisture content and number of the freezing and thawing cycle. Relationship curves of the initial moisture content (Figure 6) and the number of the freezing and thawing cycles (Figure 7) with mechanical parameters of the frozen soil were gained through additional experiments.

Figure 6(a) reveals that cohesion of the frozen soil sample presents a linear function decrease with the increase of moisture content, which follows the formula as

$$
C=-a \Delta T m_{c}+b \Delta T
$$

where $C$ is cohesion; $a$ and $b$ are the parameters associated with the temperature difference, where $a=0.008 \Delta T+1.376$ 
TABLE 1: Orthogonal experiment design and results.

\begin{tabular}{|c|c|c|c|c|c|}
\hline Number & Moisture content (\%) & $\begin{array}{c}\text { Number of the freezing } \\
\text { and thawing cycles }\end{array}$ & Temperature $\left({ }^{\circ} \mathrm{C}\right)$ & $C(\mathrm{kPa})$ & $\varphi\left({ }^{\circ}\right)$ \\
\hline (1) & 15.3 & 1 & -5 & 31.9 & 20.9 \\
\hline (2) & 15.3 & 2 & -10 & 27.1 & 19.8 \\
\hline (3) & 15.3 & 3 & -15 & 25.2 & 18.2 \\
\hline (4) & 15.3 & 5 & -20 & 22.7 & 17.2 \\
\hline (5) & 18.1 & 1 & -10 & 25.8 & 20.5 \\
\hline (6) & 18.1 & 2 & -5 & 23.1 & 19.8 \\
\hline (7) & 18.1 & 3 & -20 & 19.6 & 17.5 \\
\hline (8) & 18.1 & 5 & -15 & 17.9 & 16.8 \\
\hline (9) & 20.3 & 1 & -15 & 21.7 & 19.9 \\
\hline (10) & 20.3 & 2 & -20 & 18.7 & 18.6 \\
\hline (11) & 20.3 & 3 & -5 & 18.2 & 17.6 \\
\hline (12) & 20.3 & 5 & -10 & 15.3 & 16.7 \\
\hline (13) & 23 & 1 & -20 & 17.2 & 19.4 \\
\hline (14) & 23 & 2 & -15 & 15.6 & 18.2 \\
\hline (15) & 23 & 3 & -10 & 13.7 & 17.2 \\
\hline (16) & 23 & 5 & -5 & 12.7 & 16.4 \\
\hline
\end{tabular}

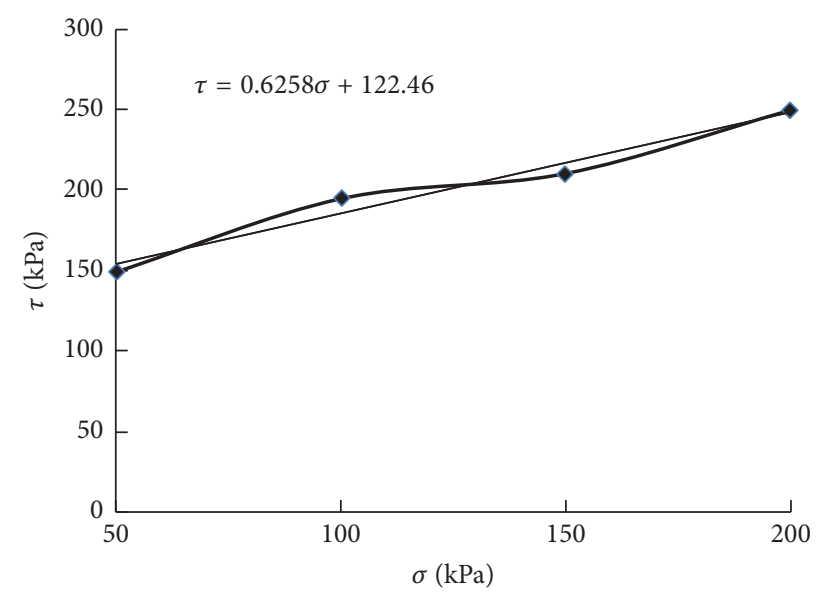

Figure 5: Mechanical parameters fitting results.

and $b=0.095 \Delta T+52.77 ; m_{c}$ is moisture content; $\Delta T$ is the temperature difference.

Such decrease slows down gradually. This is mainly because the increase of moisture content thickens the thin layer of water absorbed by particles in the rock specimens, which increases the distance between internal particles and weakens their connection strength.

In Figure 6(b), a quadratic function decrease of internal friction angle is observed with the increase of moisture content. Such decrease accelerates gradually, which can be described as follows:

$$
\varphi=-d \Delta T m_{c}^{2}+e \Delta T m_{c}+f \Delta T,
$$

where $\varphi$ is internal friction angle; $d, e$, and $f$ are the parameters associated with the temperature difference, where $d=-0.00063 \Delta T+0.0355, e=-0.023 \Delta T+1.229$, and $f=0.189 \Delta T+10.74 ; m_{c}$ is moisture content; $\Delta T$ is the temperature difference.

When pores between particles are filled with water, the thickness of water film increases and the effective contact area of particles decreases, so that the friction coefficient reduces correspondingly. According to test results, frozen soil sample has a critical moisture content. Once exceeding this critical value, the internal friction angle of the soil mass will decrease quickly with the further increase of moisture content.

In Figure 7(a), cohesion of specimens reduces exponentially with the increase of the freezing and thawing cycle. During the freezing period, ice crystals produced in pores destroy internal connection of soil particles and thereby weaken the soil mass structure. Several cycles of freezing and thawing will destroy the internal connection of particles, resulting in continuous decrease of cohesion. In Figure 7(b), the internal friction angle decreases exponentially with the increase of freezing and thawing cycle. The freezing and thawing cycles damage the original porous features in specimens, thus changing the internal skeleton. After the freezing and thawing cycles, both contact points and the friction between internal particles are reduced, thus decreasing the internal friction angle. It can be seen from Figure 7 that the reduction of cohesion and internal friction angle slows down significantly after three freezing and thawing cycles. This demonstrates that the first three freezing and thawing cycles could weaken cohesion and internal friction angle of rock and soil greatly, but they will become stable as the number of cycles further increase.

\section{Computational Simulation Analysis}

Temperature field and stress field of the soft rock slope are sensitive to temperature changes. By using the FLAC software, the influences of these factors on the slope stability 


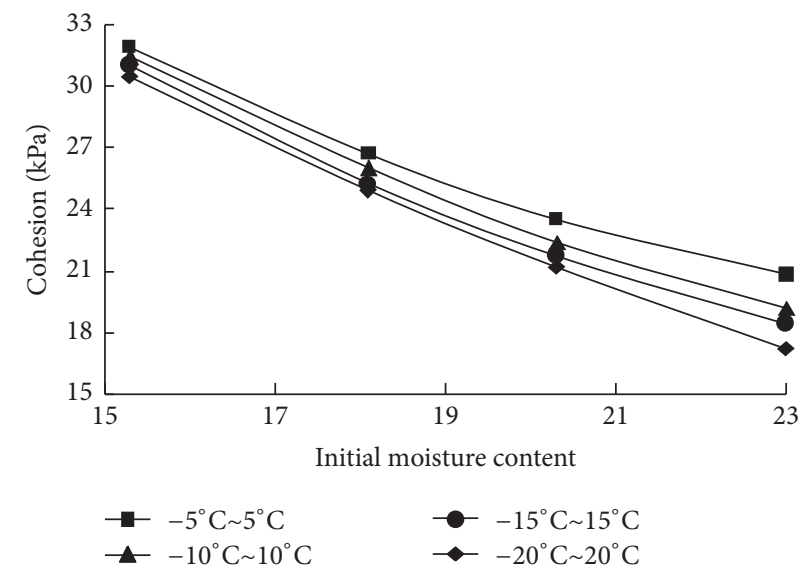

(a) Cohesion

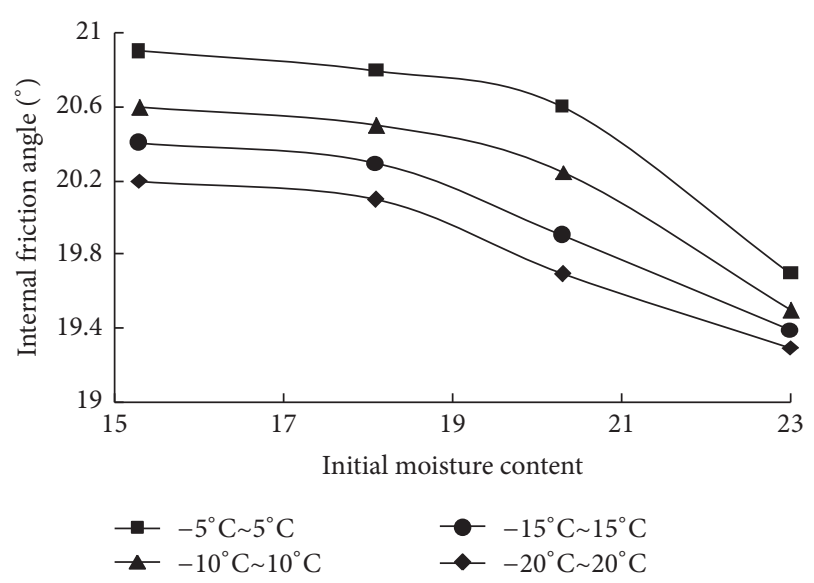

(b) Internal friction angle

FIGURE 6: Relationship curve between initial moisture content and mechanical parameters.

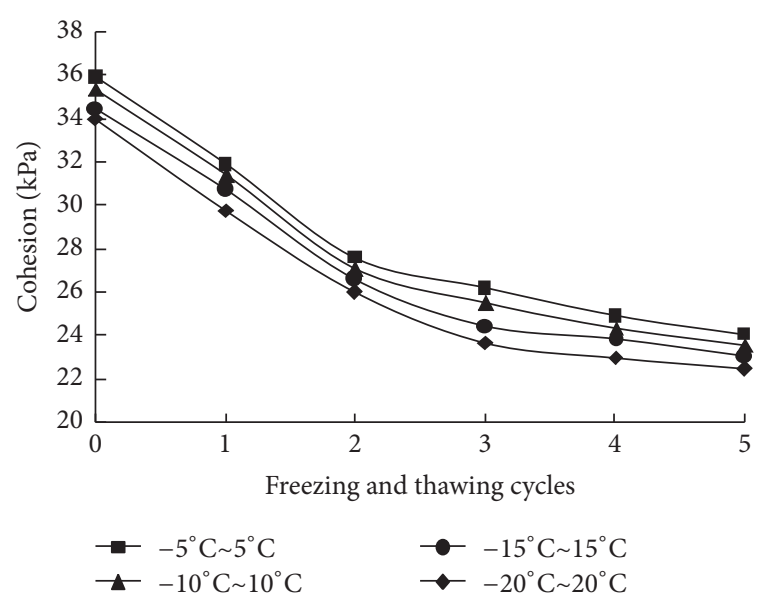

(a) Cohesion

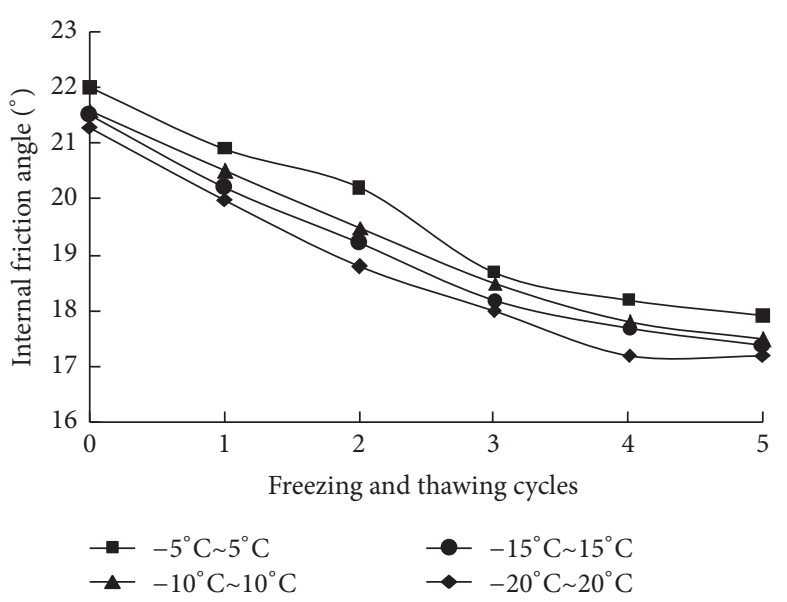

(b) Internal friction angle

FIGURE 7: The change of cohesion and internal friction angle with the freezing and thawing cycles.

of the Wulin mine during freezing and thawing cycles were analyzed. A slope model with $1: 1$ scale of the actual geometric size was established. The slope height and angle are $10 \mathrm{~m}$ and $65^{\circ}$, respectively. The whole model was divided into 1,125 grids (Figure 8). The slope model has displacement constraint and temperature constraint. For displacement boundary condition, the two sides use normal constraint and the bottom use full displacement constraint. For temperature boundary condition, the upper slope surface chooses the first type of boundary condition and temperature is set as the minimum air temperature of the month. In other words, temperature gradient is set as the maximum temperature difference of the month. Sides of the slope are set as thermal insulation conditions, while model bottom considers terrestrial heat effect and is set constant. The involved parameters used in the numerical simulation model are listed in Table 2.

According to the on-site slope structure and tested physi$\mathrm{cal}$ and mechanical parameters of freezing and thawing rocks, a simulation analysis of the slope stability during different stages of the freezing and thawing cycle was conducted. This simulation disclosed the evolution of slope stability coefficient during the freezing and thawing cycle. The original rock gravity $(\gamma)$, internal friction angle $(\varphi)$, cohesion $(C)$, moisture content, slope angle $(\beta)$, and height $(H)$ are $18.3 \mathrm{kN} / \mathrm{m}^{3}$, $21.3^{\circ}, 34.5 \mathrm{kPa}, 15.3 \%, 65^{\circ}$, and $10 \mathrm{~m}$, respectively. Based on the associated flow rule of FLAC that is commonly used to analyze the stability of slope, it is concluded that the stability coefficient of the original slope is 1.51, as shown in Figure 9.

4.1. Freezing Period. To accurately disclose the influence of a single factor on the freezing and thawing slope stability, the variable-controlled approach was applied. Firstly, the moisture content of the freezing region was kept as $15.3 \%$ and the maximum thickness of the freezing soil layer was set to $2 \mathrm{~m}$. The physical mechanical parameters of normal and freezing region are as shown in Table 3 . The change of the slope stability coefficient with the freezing depth $(0.5 \mathrm{~m}, 1 \mathrm{~m}$, $1.5 \mathrm{~m}$, and $2 \mathrm{~m}$ ) is analyzed as shown in Figure 10.

Figure 10 shows that stability coefficient increases with the increase of freezing thickness. Such increase accelerates 


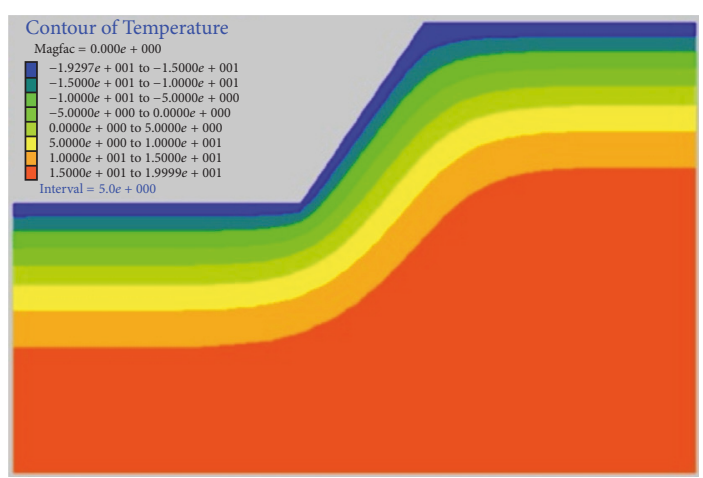

(a) Temperature field distribution

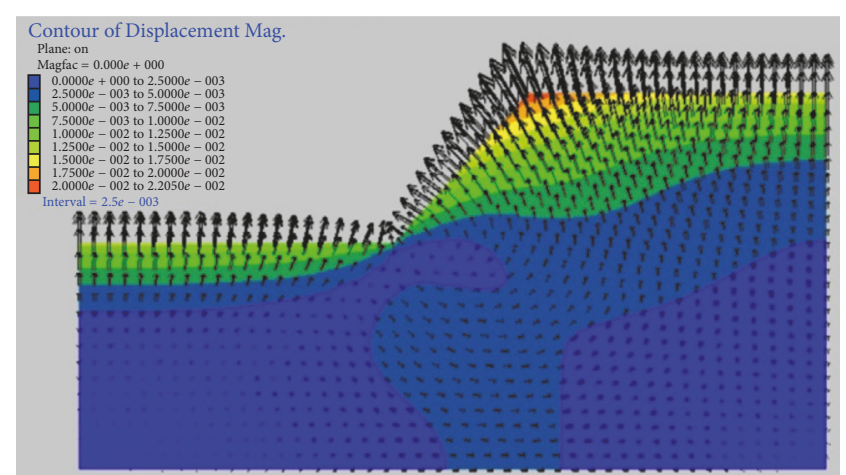

(b) Frost heaving force vector

FIGURE 8: Simulation results of temperature field and frost heaving force for slope.

TABLE 2: The involved parameters used in the numerical simulation model.

\begin{tabular}{|c|c|c|c|c|c|c|c|c|}
\hline Temperature $/{ }^{\circ} \mathrm{C}$ & -20 & -10 & -5 & -1 & 1 & 5 & 10 & 19 \\
\hline Thermal conductivity/W/(m $\left.\mathrm{m}^{\circ} \mathrm{C}\right)$ & 1.36 & 1.36 & 1.36 & 1.36 & 1.15 & 1.15 & 1.15 & 1.15 \\
\hline Specific heat capacity $/ \mathrm{J} /\left(\mathrm{kg}^{\circ} \mathrm{C}\right)$ & 1746.2 & 1746.2 & 1746.2 & 1746.2 & 2133.6 & 2133.6 & 2133.6 & 2133.6 \\
\hline
\end{tabular}

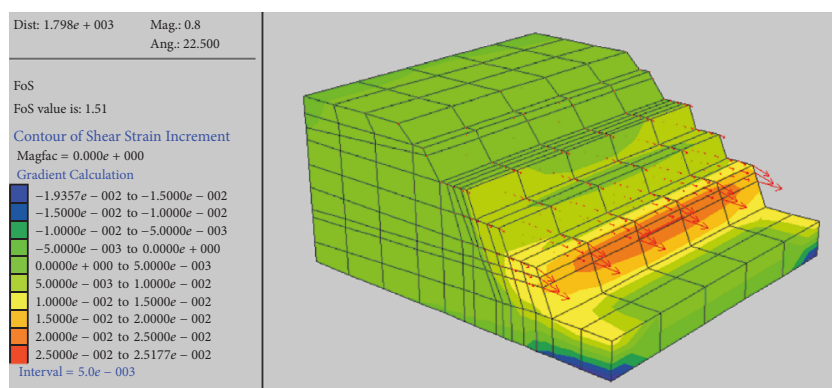

Figure 9: Slope stability analysis of Wulin open-pit mine.

TABle 3: Physicomechanical parameters of normal and freezing region.

\begin{tabular}{lccc}
\hline Number & $\begin{array}{c}\text { Unit weight } \\
(\gamma)\end{array}$ & $\begin{array}{c}\text { Cohesion } \\
(C)\end{array}$ & $\begin{array}{c}\text { Internal friction } \\
\text { angle }(\varphi)\end{array}$ \\
\hline Normal region & 20.5 & 27.1 & 19.8 \\
Freezing region & 19.2 & 39.9 & 20.9 \\
\hline
\end{tabular}

gradually. The slip mass in the slope shows basically the same geometric shape of a circular arc. The freezing depth obviously influences the shape of the sliding surface.

4.2. Thawing Period. Influence of thawing layer thickness $(0.5 \mathrm{~m}, 1 \mathrm{~m}, 1.5 \mathrm{~m}$, and $2 \mathrm{~m})$ on slope stability was analyzed. Mechanical parameters were chosen according to test results under $15.3 \%, 18.10 \%, 20.30 \%$, and $23 \%$ moisture contents. The change of the slope stability coefficient with the thawing depth is shown in Figure 11.

According to Figure 11, the stability coefficient is inversely proportional to the thawing depth. Under $15.3 \%$ and $18.1 \%$ moisture content, the slope stability coefficient shows almost a linear decrease with the increase of thawing depth. Under

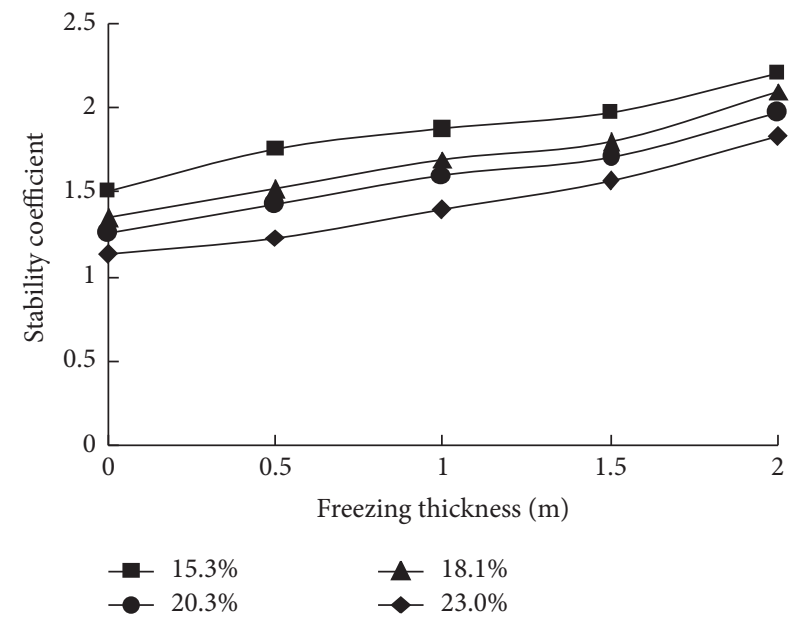

FIGURE 10: Variation of stability coefficient with freezing depth.

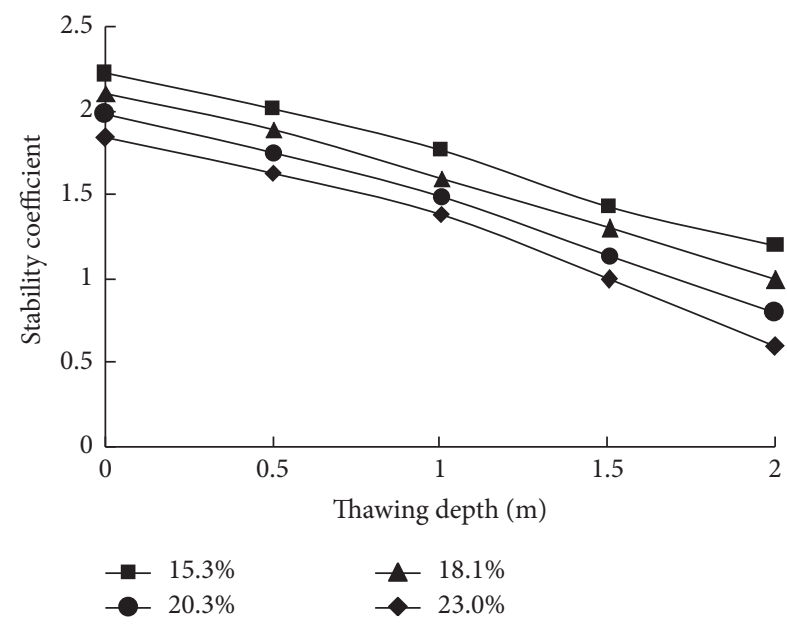

FIGURE 11: Variation of slope stability coefficient with thawing depth. 


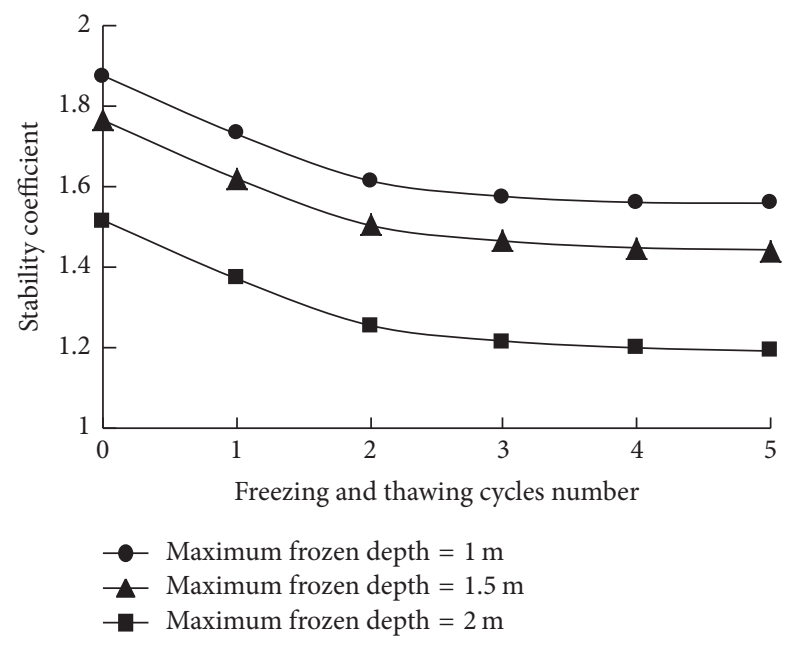

FIGURE 12: Variation of slope stability coefficient with number of the freezing and thawing cycles.

$20.3 \%$ and $23 \%$ moisture content, the slope stability coefficient decreases exponentially with the increase of thawing depth. It reveals that higher thickness of the thawing area not only reduces the stability coefficient but also changes the shape and region of the slip mass. The thicker the thawing layer, the larger the area with the risk of sliding surface in the thawing region.

4.3. Effect of Number of the Freezing and Thawing Cycles on Slope Stability. Rock structure as well as physical and mechanical parameters of soft rock slope deteriorate significantly after the freezing and thawing cycle. Each freezing and thawing cycle deteriorates slope rock and stability coefficient to a certain extent. Relationships between the number of the freezing and thawing cycles $(1,2,3,4$, and 5) and slope stability coefficient are analyzed as shown in Figure 12.

Seen from Figure 12, after experiencing several freezing and thawing cycles, given the same freezing depth and moisture content, the slope stability coefficient shows a negative exponential decrease as the freezing and thawing cycles increase, which discloses an important engineering problem. After the slope is formed, the first freezing and thawing cycle deteriorates most of the overall slope stability. Once the number of freezing and thawing cycle exceeds 3 times, the slope stability coefficient decreases slightly and tends to be stable.

\section{Field Investigation}

In Wulin surface mine, the mining direction is from west to east; thus, the high and steep end-wall slopes were formed at both north and south sides of the mine. The slope is located at the eastern part of the end-slope within the scope of $80 \mathrm{~m}$. Under the influence of unloading produced by excavation, the slope appeared as an obvious deformation along the weak layer, as shown in Figure 13. The fragmentation degree and cracks of soft rock in the slope were significantly increased after experienced a freezing and thawing process. This phenomenon embodies the effect of freezing and thawing cycle action on the deformation of newly formed slope.

To estimate the deformation of slope in the mining process, three sets of monitoring equipment were set up on the south end-slope and the west slope. There are three sets of monitoring equipment arranged at the same height, which were named as P2, P4, and P6. In addition, the slopes monitored by $\mathrm{P} 2$ and $\mathrm{P} 4$ existed for 5 years and 2 years, while the slope under the monitor of P6 is a new slope. The displacement data of the three monitoring points from November 2015 to March 2016 is shown in Figure 14.

Seen from the monitoring data in Figure 14, after one freezing and thawing cycle, the largest displacement appeared at P6, and the smaller displacement appeared at P4. Furthermore the minimum displacement is appeared at P2 after it experienced five times freezing and thawing cycles. The slope displacement distribution is the same as the slope stability changing rule with different times of freezing and thawing cycles. This is why slopes that have existed for years maintain basically the same stability with the increase of freezing and thawing cycle. However, open-pit mines with continuous developing slopes are highly sensitive to freezing and thawing cycle and deserve higher attentions.

The experimental research has concluded that the moisture content as well as the number of the freezing and thawing cycles significantly influences the strength of freezing soft rock specimens. However, there is no explicit conclusion concerning the influence degree of these key factors on rock strength and stability of the soft rock slope. Test results demonstrate that mechanical parameters of soft rock and slope stability coefficient decrease in a negative exponential pattern with the increase of freezing and thawing cycle. But after three freezing and thawing cycles, the slope stability is only influenced to a lesser extent with the further increase of the freezing and thawing cycle. Moisture content significantly affects mechanical parameters of soft rock and slope stability all the time. The higher the moisture content is, the more seriously the soft rock strength and slope stability are influenced. Based on these influence laws, when the number of the freezing and thawing cycles is smaller than three times, the soft rock slope stability is mostly affected. At the same time, when the number of the freezing and thawing cycles is larger than three times, the moisture content influences the soft rock slope stability mostly. To determine the dominant influencing factor of soft rock slope stability, the combination effect of specific rock properties and parameters as well as the number of freezing and thawing cycle the slope have experienced need to be considered. Further researches will focus on the coupling relationship of these two influencing factors, their relative importance, and governing strategies of soft rock slope in seasonal freezing soil areas.

\section{Conclusions}

The freezing and thawing cycles affect rock strength of soft rock slope significantly. The experiment shows that moisture content and number of the freezing and thawing cycles are the two important influencing factors for mechanical 


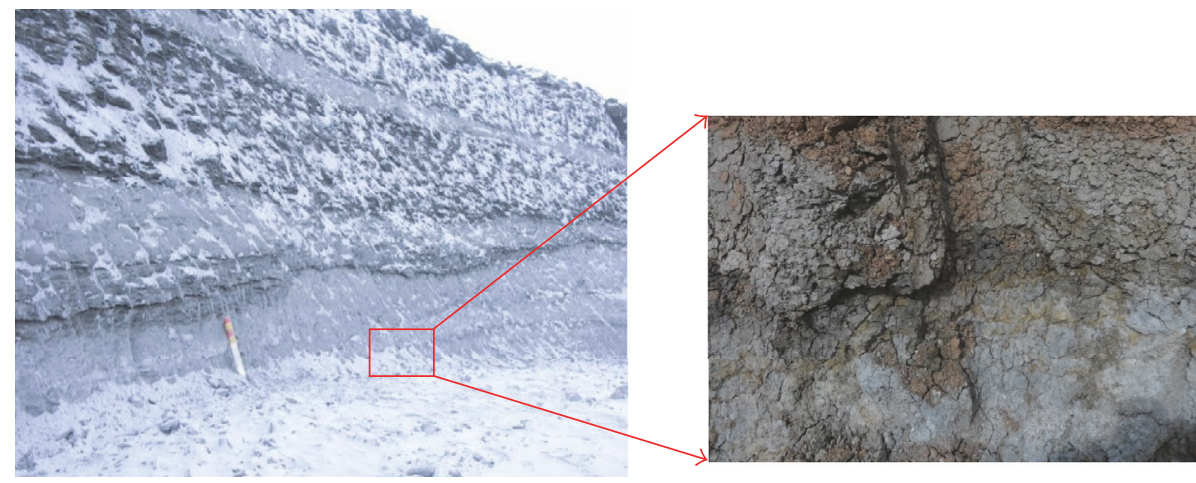

FIGURE 13: The deformation and fragmentation of new slope after undergoing the freezing and thawing cycle process.

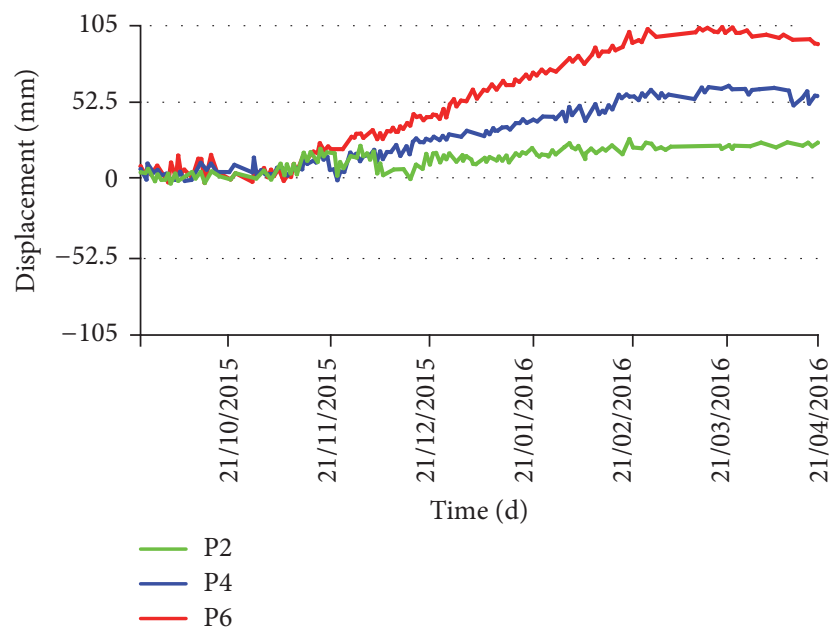

Figure 14: The displacement data of three different monitoring points.

parameters of soft rock. Their functional relationships with basic mechanical parameters of soft rock are gained. This paper concludes the following:

(1) The cohesion of frozen soil specimens presents a quadratic function decrease with the increase of moisture content. Such decrease slows down gradually. The internal friction angle of the frozen soil specimens shows a negative exponential decrease against the increase of moisture content. Such decrease accelerates gradually. As the freezing and thawing cycles increase, both cohesion and internal friction angle of frozen soil specimens decrease exponentially. Such decrease slows down significantly after three freezing and thawing cycles.

(2) Slope stability coefficient is proportional to freezing layer thickness. With the increase of thawing layer thickness, slope stability coefficient decreases linearly when moisture content of the soft rock is smaller than $20.3 \%$ but decreases exponentially when moisture content is larger.

(3) After experiencing several freezing and thawing cycles, given the same freezing depth and moisture content, the slope stability coefficient shows a negative exponential decrease as the freezing and thawing cycles increase. After three freezing and thawing cycles, the slope stability coefficient decreases slightly and tends to be stable. Therefore, strip mines with continuous developing slopes are highly sensitive to the number of freezing and thawing cycles. This the key technical problem of strip mines in seasonal freezing soil areas.

\section{Conflicts of Interest}

The authors declare that there are no conflicts of interest regarding the publication of this paper.

\section{Acknowledgments}

The authors acknowledge financial support by the Fundamental Research Funds for the Central Universities (2015QNA60).

\section{References}

[1] T. W. J. van Asch, J.-P. Malet, L. P. H. van Beek, and D. Amitrano, "Techniques issues and advances in numerical modelling of landslide hazard," Bulletin de la Société Géographique de France, vol. 178, no. 2, pp. 65-88, 2007.

[2] G.-H. Xie, J.-S. Zhang, and R.-G. Liu, "Application of matrixbased system reliability method in complex slopes," Journal of Central South University, vol. 20, no. 3, pp. 812-820, 2013.

[3] W. S. Yoon, U. J. Jeong, and J. H. Kim, "Kinematic analysis for sliding failure of multi-faced rock slopes," Engineering Geology, vol. 67, no. 1-2, pp. 51-61, 2002.

[4] D.-Q. Li, Z.-Y. Yang, Z.-J. Cao, S.-K. Au, and K.-K. Phoon, "System reliability analysis of slope stability using generalized subset simulation," Applied Mathematical Modelling: Simulation and Computation for Engineering and Environmental Systems, vol. 46, pp. 650-664, 2017.

[5] Z. G. Qian, A. J. Li, A. V. Lyamin, and C. C. Wang, "Parametric studies of disturbed rock slope stability based on finite element limit analysis methods," Computers \& Geosciences, vol. 81, pp. 155-166, 2017.

[6] G. Martelloni and F. Bagnoli, "Infiltration effects on a twodimensional molecular dynamics model of landslides," Natural Hazards, vol. 73, no. 1, pp. 37-62, 2014. 
[7] I. Alcántara-Ayala, "Geomorphology, natural hazards, vulnerability and prevention of natural disasters in developing countries," Geomorphology, vol. 47, no. 2-4, pp. 107-124, 2002.

[8] G. B. Crosta and F. Agliardi, "Failure forecast for large rock slides by surface displacement measurements," Canadian Geotechnical Journal, vol. 40, no. 1, pp. 176-191, 2003.

[9] C. Cloutier, F. Agliardi, G. B. Crosta et al., "The First International Workshop on Warning Criteria for Active Slides: technical issues, problems and solutions for managing early warning systems," Landslides , vol. 12, no. 1, pp. 205-212, 2014.

[10] A. Mufundirwa, Y. Fujii, and J. Kodama, "A new practical method for prediction of geomechanical failure-time," International Journal of Rock Mechanics and Mining Sciences, vol. 47, no. 7, pp. 1079-1090, 2010.

[11] V. Wirz, J. Beutel, S. Gruber, S. Gubler, and R. S. Purves, "Estimating velocity from noisy GPS data for investigating the temporal variability of slope movements," Natural Hazards and Earth System Sciences, vol. 14, no. 9, pp. 2503-2520, 2014.

[12] N. Casagli, F. Catani, C. Del Ventisette, and G. Luzi, "Monitoring, prediction, and early warning using ground-based radar interferometry," Landslides, vol. 7, no. 3, pp. 291-301, 2010.

[13] T. C. Chen, M. R. Yeung, and N. Mori, "Effect of water saturation on deterioration of welded tuff due to freeze-thaw action," Cold Regions Science and Technology, vol. 38, no. 2-3, pp. 127-136, 2004.

[14] K. Watanabe and M. Mizoguchi, "Amount of unfrozen water in frozen porous media saturated with solution," Cold Regions Science and Technology, vol. 34, no. 2, pp. 103-110, 2002.

[15] Q. Hu, Q. Cai, L. He, X. Yang, T. Ye, and R. Shi, "Determination of the peak and residual shear strengths of the sandwich material in slopes," Advances in Materials Science and Engineering, vol. 2017, Article ID 9641258, 15 pages, 2017.

[16] R. Huang, H. Xiao, N. Ju, and J. Zhao, "deformation mechanism and stability of a rocky slope," Journal of China University of Geosciences, vol. 18, no. 1, pp. 77-84, 2007.

[17] S. Mohammadi and H. A. Taiebat, "A large deformation analysis for the assessment of failure induced deformations of slopes in strain softening materials," Computers \& Geosciences, vol. 49, pp. 279-288, 2013.

[18] E. Conte, F. Silvestri, and A. Troncone, "Stability analysis of slopes in soils with strain-softening behaviour," Computers \& Geosciences, vol. 37, no. 5, pp. 710-722, 2010.

[19] A. Troncone, E. Conte, and A. Donato, "Two and three-dimensional numerical analysis of the progressive failure that occurred in an excavation-induced landslide," Engineering Geology, vol. 183, pp. 265-275, 2014.

[20] L. Han, W. Zhou, J. Shu, S. Wang, and Q. Meng, "Study of plane sliding timeliness stability and structure optimization of soft rock slope," Journal of China University of Mining and Technology, vol. 43, no. 3, pp. 395-401, 2014.

[21] L. Han, W. Zhou, Q.-X. Cai, J.-S. Shu, H.-W. Jing, and X. Li, "Experimental study on remodeling strength of granular materials under different loads and lengths of time," Journal of Central South University, vol. 22, no. 7, pp. 2783-2790, 2015.

[22] G.-S. Yang and Y.-B. Pu, "Initial discussion on the damage propagation of rock under the frost and thaw condition," Journal of the China Coal Society, vol. 27, no. 4, pp. 357-360, 2002.

[23] L. Han, J. S. Shu, W. Zhou, S. W. Wang, Q. W. Meng, and J. K. $\mathrm{Xu}$, "Progressive failure characteristics and stability analysis of folded sliding surface," Journal of China University of Mining \& Technology, vol. 44, no. 1, pp. 46-53, 2015.
[24] Z. Xuefu, L. Yuanming, Y. Wenbing, Z. Shujuan, and X. Jianzhang, "Forecast analysis of the refreezing of Kunlun mountain permafrost tunnel on Qing-Tibet railway in China," Cold Regions Science and Technology, vol. 39, no. 1, pp. 19-31, 2004.

[25] K. M. Neaupane and T. Yamabe, "A fully coupled thermo-hydromechanical nonlinear model for a frozen medium," Computers \& Geosciences, vol. 28, no. 8, pp. 613-637, 2001.

[26] Y. M. Lai, Z. W. Wu, Y. L. Zhu, F. Ling, and L. N. Zhu, "Analytical viscoelastic solution for frost force of cold regional tunnels," Journal of the China Railway Society, vol. 21, no. 6, pp. 70-74, 1999 (Chinese).

[27] S. Zhang, Y. Lai, X. Zhang, Y. Pu, and W. Yu, "Study on the damage propagation of surrounding rock from a cold-region tunnel under freeze-thaw cycle condition," Tunnelling and Underground Space Technology, vol. 19, no. 3, pp. 295-302, 2004.

[28] D. T. Nicholson, T. Dawn, and F. H. Nicholson, "Physical deterioration of sedimentary rocks subjected to experimental freeze-thaw weathering," Earth Surface Processes and Landforms, vol. 25, no. 12, pp. 1295-1307, 2000.

[29] J. Y. Li, W. Y. Xu, J. G. Cao, L. Lin, and Y. S. Guan, "Study on the mechanism of concrete destruction under frost action," Journal of Hydraulic Engineering, vol. 1, no. 1, pp. 42-50, 1999.

[30] M. Hori and H. Morihiro, "Micromechanical analysis on deterioratIon due to freezing and thawing in porous brittle materials," International Journal of Engineering Science, vol. 36, no. 4, pp. 511-522, 1998.

[31] T. Yamabe and K. M. Neaupane, "Determination of some thermo-mechanical properties of Sirahama sandstone under subzero temperature condition," International Journal of Rock Mechanics and Mining Sciences, vol. 38, no. 7, pp. 1029-1034, 2001. 

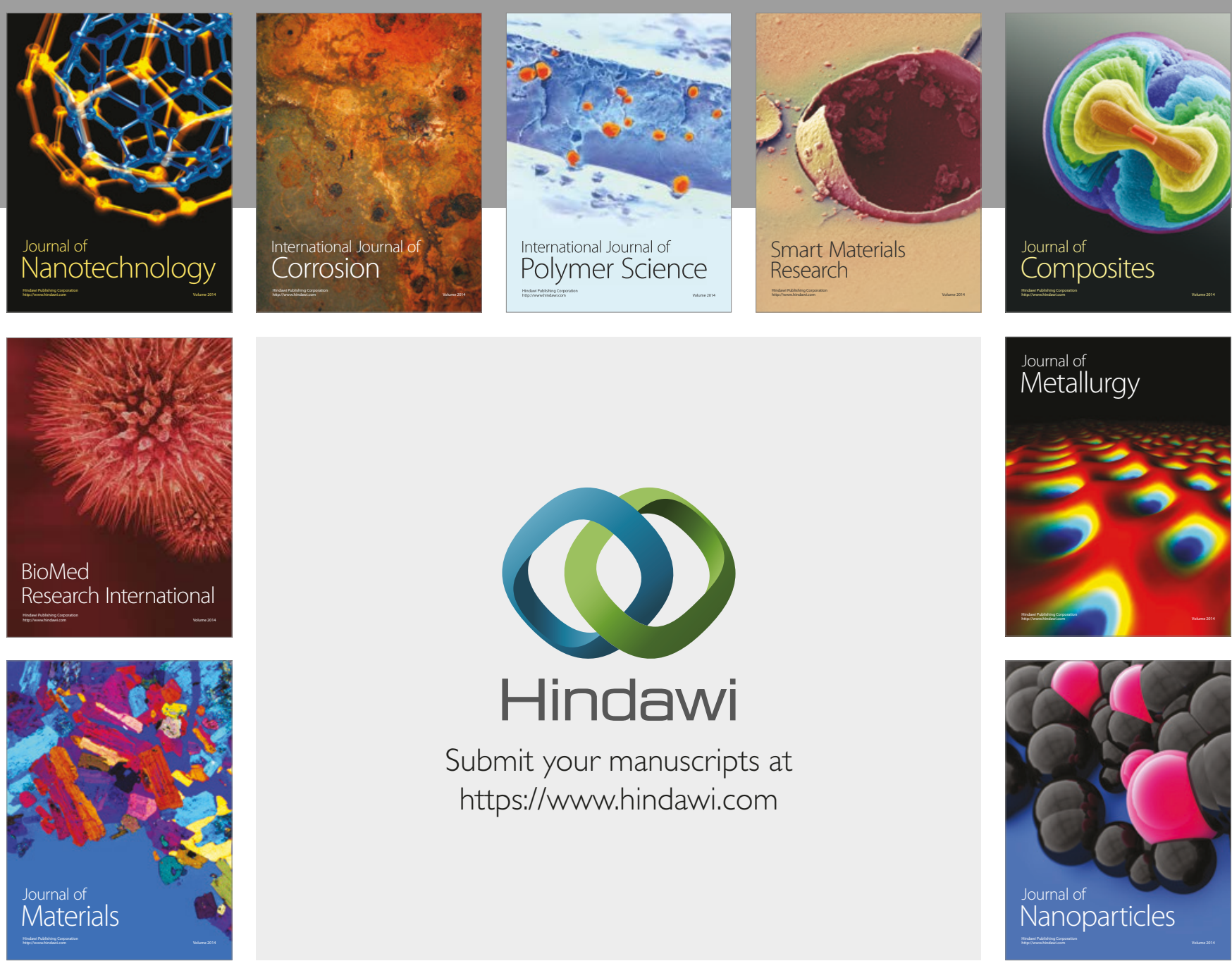

\section{Hindawi}

Submit your manuscripts at

https://www.hindawi.com
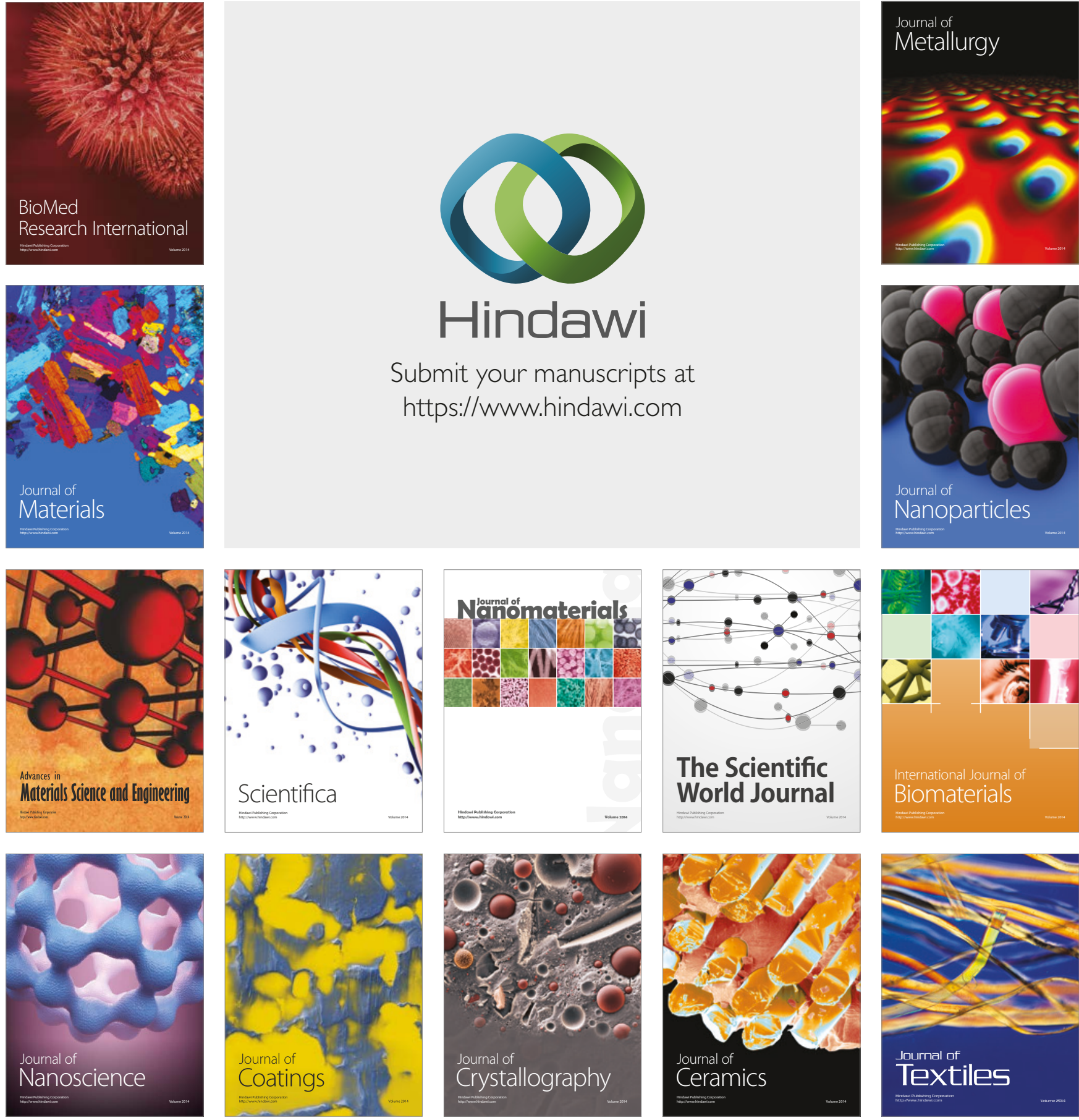

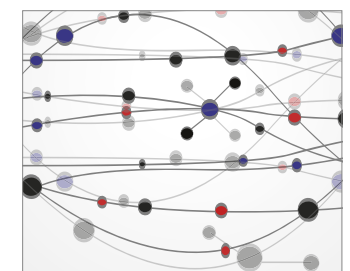

The Scientific World Journal
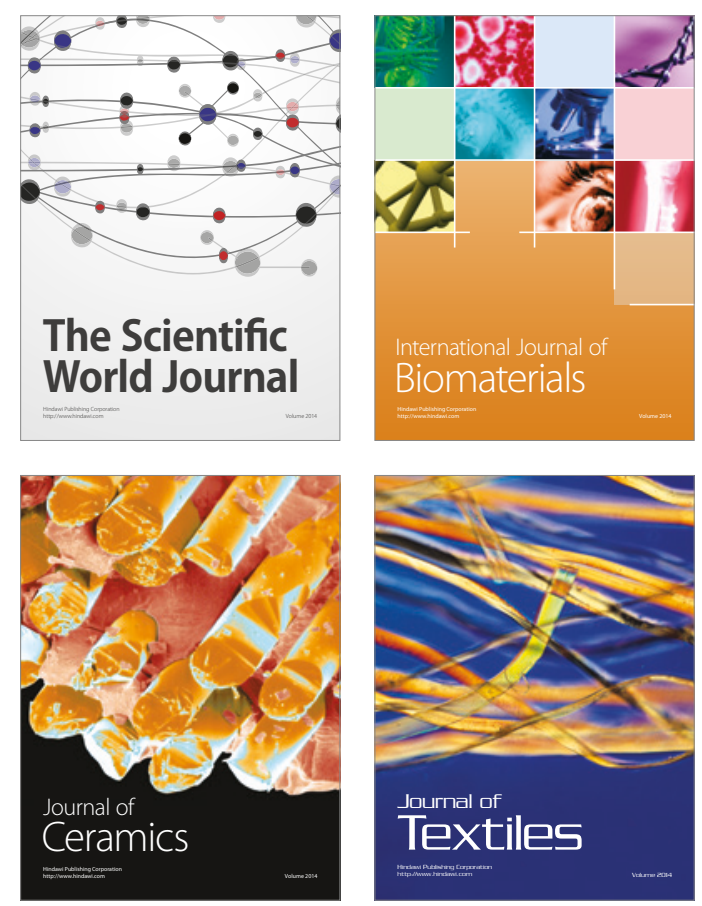